NASA/TM-2010-216746

\title{
Sensor and Actuator Needs for More Intelligent Gas Turbine Engines
}

\section{Sanjay Garg}

Glenn Research Center, Cleveland, Ohio

Klaus Schadow

Schadow Technology, San Clemente, California

Wolfgang Horn and Hugo Pfoertner

MTU Aero Engines, München, Germany

Ion Stiharu

Concordia University, Montreal, Quebec, Canada 


\section{NASA STI Program . . . in Profile}

Since its founding, NASA has been dedicated to the advancement of aeronautics and space science. The NASA Scientific and Technical Information (STI) program plays a key part in helping NASA maintain this important role.

The NASA STI Program operates under the auspices of the Agency Chief Information Officer. It collects, organizes, provides for archiving, and disseminates NASA's STI. The NASA STI program provides access to the NASA Aeronautics and Space Database and its public interface, the NASA Technical Reports Server, thus providing one of the largest collections of aeronautical and space science STI in the world. Results are published in both non-NASA channels and by NASA in the NASA STI Report Series, which includes the following report types:

- TECHNICAL PUBLICATION. Reports of completed research or a major significant phase of research that present the results of NASA programs and include extensive data or theoretical analysis. Includes compilations of significant scientific and technical data and information deemed to be of continuing reference value. NASA counterpart of peer-reviewed formal professional papers but has less stringent limitations on manuscript length and extent of graphic presentations.

- TECHNICAL MEMORANDUM. Scientific and technical findings that are preliminary or of specialized interest, e.g., quick release reports, working papers, and bibliographies that contain minimal annotation. Does not contain extensive analysis.

- CONTRACTOR REPORT. Scientific and technical findings by NASA-sponsored contractors and grantees.
- CONFERENCE PUBLICATION. Collected papers from scientific and technical conferences, symposia, seminars, or other meetings sponsored or cosponsored by NASA.

- SPECIAL PUBLICATION. Scientific, technical, or historical information from NASA programs, projects, and missions, often concerned with subjects having substantial public interest.

- TECHNICAL TRANSLATION. Englishlanguage translations of foreign scientific and technical material pertinent to NASA's mission.

Specialized services also include creating custom thesauri, building customized databases, organizing and publishing research results.

For more information about the NASA STI program, see the following:

- Access the NASA STI program home page at http://www.sti.nasa.gov

- E-mail your question via the Internet to help@ sti.nasa.gov

- Fax your question to the NASA STI Help Desk at $443-757-5803$

- Telephone the NASA STI Help Desk at 443-757-5802

- Write to: NASA Center for AeroSpace Information (CASI) 7115 Standard Drive Hanover, MD 21076-1320 
NASA/TM-2010-216746

Sensor and Actuator Needs for More Intelligent Gas Turbine Engines

Sanjay Garg

Glenn Research Center, Cleveland, Ohio

Klaus Schadow

Schadow Technology, San Clemente, California

Wolfgang Horn and Hugo Pfoertner

MTU Aero Engines, München, Germany

Ion Stiharu

Concordia University, Montreal, Quebec, Canada

Prepared for the

Turbo Expo 2010

sponsored by the American Society of Mechanical Engineers (ASME)

Glasgow, Scotland, United Kingdom, June 14-18, 2010

National Aeronautics and

Space Administration

Glenn Research Center

Cleveland, Ohio 44135 
Level of Review: This material has been technically reviewed by technical management.

Available from

NASA Center for Aerospace Information 7115 Standard Drive

Hanover, MD 21076-1320
National Technical Information Service 5301 Shawnee Road Alexandria, VA 22312

Available electronically at http://gltrs.grc.nasa.gov 


\title{
Sensor and Actuator Needs for More Intelligent Gas Turbine Engines
}

\author{
Sanjay Garg \\ National Aeronautics and Space Administration \\ Glenn Research Center \\ Cleveland, Ohio 44135 \\ Klaus Schadow \\ Schadow Technology \\ San Clemente, California 92673 \\ Wolfgang Horn and Hugo Pfoertner \\ MTU Aero Engines \\ 80995 München, Germany \\ Ion Stiharu \\ Concordia University \\ Montreal, Quebec, Canada H3G 1M8
}

\begin{abstract}
This paper provides an overview of the controls and diagnostics technologies, that are seen as critical for more intelligent gas turbine engines (GTE), with an emphasis on the sensor and actuator technologies that need to be developed for the controls and diagnostics implementation. The objective of the paper is to help the "Customers" of advanced technologies, defense acquisition and aerospace research agencies, understand the state-of-the-art of intelligent GTE technologies, and help the "Researchers" and "Technology Developers" for GTE sensors and actuators identify what technologies need to be developed to enable the "Intelligent GTE" concepts and focus their research efforts on closing the technology gap. To keep the effort manageable, the focus of the paper is on "OnBoard Intelligence" to enable safe and efficient operation of the engine over its life time, with an emphasis on gas path performance.
\end{abstract}

\section{Introduction}

With the increased emphasis on aircraft safety, enhanced performance and affordability, and the need to reduce the environmental impact of aircraft, there are many new challenges being faced by the designers of aircraft propulsion systems. There is significant investment being made by various NATO (North Atlantic Treaty Organization) countries in development of advanced controls and health management technologies that will help meet these challenges through the concept of Intelligent Propulsion Systems. The key enabling technologies for an Intelligent Propulsion System are: the increased efficiencies of components through active control; advanced diagnostics and prognostics integrated with intelligent engine control to enhance operational reliability and component life; and distributed control with smart sensors and actuators in an adaptive fault tolerant architecture.
Development of appropriate sensor and actuation systems is critical to affordable and reliable implementation of the technologies for a more intelligent gas turbine engine.

In 2004, NATO RTO (Research and Technology Organization) established an Applied Vehicle Technology (AVT) Task Group to review the status of technologies that contribute to a "More Intelligent Gas Turbine Engine" and recommend technology development needs with an emphasis on the type of sensors and actuators needed to enable these technologies. The Task Group completed its work in 2008 and published a NATO RTO report documenting the findings in April 2009 (Ref. 1). The objective of the report was twofold: i) Help the "Customers" (NATO defense acquisition and aerospace research agencies) understand the state-of-the-art of intelligent engine technologies, how these technologies can help them meet challenging performance and operational reliability requirements for aircraft engines, and what investments need to be made in sensor and actuator technologies to enable the various capabilities of "Intelligent Engines" so that limited resources are used in a most efficient manner; and ii) Help the "Researchers" and "Technology Developers" identify what sensor and actuator technologies need to be developed to enable the "Intelligent Engine" concepts so that their research efforts can be focused on closing the gap from current capability to that needed to meet identified requirements, and also increase their awareness of "requirements" that need to be met other than performance (such as cost, durability, etc.) to enable the transition of technology to a product.

The overall technology areas that fall under the umbrella of "intelligent engines" are too broad to be covered by one report. To keep the effort manageable, the focus of the report was on "On-Board Intelligence" to enable safe and efficient operation of the engine over the life time, and adapt to changing internal and external environments to provide “optimum” achievable performance based on operation mode and current conditions. 
The discussion in the report was limited to: i) description of technologies for active control of components in the gas path to enhance performance and reduce emission and noise; ii) intelligent control and condition monitoring from the overall engine gas path performance perspective; and iii) advanced control architecture concepts such as distributed engine control. This paper provides an overview of the significant findings of the report in terms of identifying the sensor and actuator needs to realize these intelligent engine concepts with the ultimate objective being to identify sensor and actuator technology development roadmaps.

The paper is organized as follows. The first section discusses various concepts for active control of engine gas path components such as inlet, compressor, combustor, turbine and nozzle, with an emphasis on performance and operating environment specifications for sensors and actuators to enable the active component control capability. The next section describes the various aspects of intelligent engine control and condition monitoring from an overall gas path system perspective and discusses the sensor needs for implementation of model based control and diagnostics. The technologies required to move from the current highly centralized engine control architecture to more distributed control architecture are then discussed. This section discusses challenges due to the harsh environment of the engine, as summarized in Figure 1, and weight and volume limitations that imply the need for developing high temperature electronics and data communication hardware to enable smart, self diagnostic sensors and actuators to fully utilize the benefits of distributed control architecture. The requirements, other than performance, that a sensor or actuator technology needs to meet in order to be considered for implementation on an engine are then briefly discussed in the next section. The paper concludes by summarizing a roadmap to intelligent engine technology development.

\section{Actively Controlled Components}

Modern aircraft engines face challenging performance requirements driven by customers' and public needs. To achieve these requirements, the engine has to operate at the physical limits which are given by material and gas properties. Gas turbines also face a variety of challenges during operation such as: Inlet flow distortion and separation; Compressor surge and stall; Combustion instabilities; Flow separations on airfoils; Flutter and high cycle fatigue; and Engine noise (Ref. 2). The traditional engine control design problem has been to transition the operating point of the engine from one point to another in the most expedient manner without compromising any predefined limits. The presence of full authority digital engine controllers (FADECs) on most modern aircraft offers the possibility to take advantage of more sophisticated control techniques. The rapid progress of micro processing capability combined with advances in sensor technology, becoming cheaper, faster, and smaller, offer new possibilities of effective engine control.

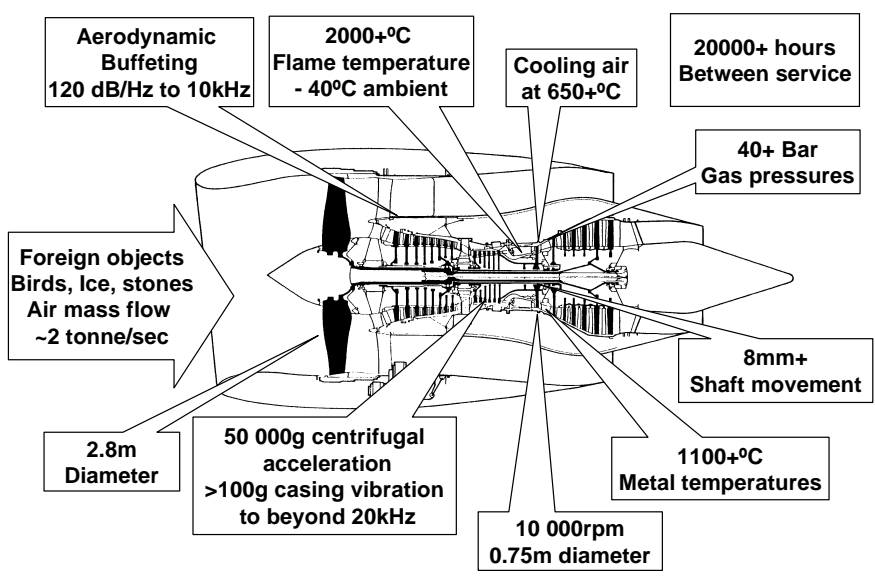

Figure 1.-Environment within an aircraft gas turbine engine.

Current engine components are designed with large safety margins to ensure safe operation in worst case deterioration and operating conditions. The potentially available performance of engine components often is not exploitable due to the fact that different limits and margins have to be taken into account during the design (Ref. 3). One way to overcome this situation is the use of active elements in gas turbine engines. The idea behind active control is the ability to sense the current condition and to react with an adequate control action. Unstable operating conditions can be avoided by changing the component behavior. Extreme or deteriorated conditions can be covered by adapting the component to the current situation. Thus, the components can be optimized at the design stage without compromising performance by operational limits or singular events. Furthermore, an actively controlled engine will offer the best possible performance at any flight condition and point of time.

An important aspect of active control is its system nature. Although a control system consists of many separate components, it is essential to keep an overall systems perspective in mind when designing these subcomponents. The physical process is determined by the interaction of different phenomena and the interaction of individual elements. Adding feedback control can change the system dynamics and a controlled component can have different properties. An interdisciplinary (fluids, control, structures, instrumentation,...) approach is needed for success because the systems aspects are critical (Refs. 4 and 5).

In the following, the benefits of active control technologies to further increase the operational flexibility and efficiency of each engine component is briefly reviewed, including highlighting the physical control processes and characterizing the sensor and actuator technology needs. The sensors and actuators have to operate reliably in the gas path pressure and temperature conditions summarized in Figure 1.

\section{Active Inlet Flow and Noise Control}

The main purpose of an engine intake is to provide the first compressor stage with nearly clean and undistorted air. For 
commercial aircraft the engine intake is integrated into the nacelle. The challenge for these configurations is the increased tolerance against cross wind which usually requires thicker intake lips. But thicker intake lips generate significantly higher aerodynamic losses and, consequently, higher SFC (Specific Fuel Consumption) during cruise. The application of active or deployable-on-command passive flow control mechanisms enable the avoidance of the design antagonism. For military aircraft, the engine is completely embedded into the aircraft frame in order to reduce the aerodynamic losses and radar pattern of the airframe. The intake duct for these applications is formed as an S-shape duct connecting the intake opening in the airframe with the front stage of the installed engine in order to improve the stealth characteristic of the aircraft. The purpose of the S-shape intake duct is the reorganization of the air in order to provide the compressor an undisturbed axisymmetric flow. The challenge for this type of configuration is the prevention of flow separation during the flow reorganization and turning during all flight conditions (take-off, cruise and climb).

In general, the active control of inlet flow distortions at the engine intake face (fan or low pressure compressor) can improve both the efficiency of the intake itself (by intake loss reduction) and the level of flow conformity upstream of the compressor. The reduced flow distortion reduces the jeopardy of a stalled compressor and can be traded against higher compressor efficiency. Possible active flow control devices are deployable vortex generators, pulsed micro jets or an active intake shape change. Reference 6 provides an example study of active flow control for inlets.

Active noise suppression is also a research area for inlet control. A number of concepts have been proposed to improve the effectiveness of acoustic treatment found in the inlet of commercial aircraft engines. Some of these techniques include actively modifying the porosity of the face sheet covering the inlet honeycomb structure and therefore actively changing the acoustic characteristics of the cavities in the honeycomb.

Active noise cancellation that generates noise in the aircraft engine inlet to cancel the noise generated by the fan is another concept being studied. This technology works to reduce tones - that are characteristic of the noise generated by the rotorstator interaction. The technology works to reduce noise, but the accompanying system (measurement devices, acoustics sources, and controllers) makes it difficult to package the device in a real system (Ref. 7).

Based on the above discussion, the sensor and actuator requirements for active inlet control are listed in Table 1.

TABLE 1.-SENSOR AND ACTUATOR REQUIREMENTS FOR ACTIVE INLET CONTROL

\begin{tabular}{|c|c|c|c|c|}
\hline Technology & $\begin{array}{c}\text { Sensed } \\
\text { variable }\end{array}$ & Sensor requirements & Controlled variable & Actuator requirements \\
\hline $\begin{array}{l}\text { Active noise } \\
\text { control }\end{array}$ & $\begin{array}{l}\text { Dynamic } \\
\text { pressure }\end{array}$ & $\begin{array}{l}\text { - } 100 \mathrm{kPa} \text { differential, } \\
\text { - } 10 \mathrm{kHz} \text {, resolution-0.5\% of full } \\
\text { scale output }\end{array}$ & $\begin{array}{l}\text { - Honeycomb geometry, } \\
\text { acoustic waves }\end{array}$ & $\begin{array}{l}\text { - Piezoelectric actuator, } 2.5 \text { to } 5 \mathrm{~mm} \\
\text { deflection }\end{array}$ \\
\hline
\end{tabular}

\section{Active Fan and Compressor Control}

The compression system is one of the key elements of the aircraft engine. An efficient thermodynamic cycle requires high overall pressure ratios at a minimum amount of loss. Turbomachinery losses occur due to friction losses, secondary flows, separations and shock losses. The leakage of air between rotating and stationary parts forms another significant source of losses. The stable operation of the jet engine has to be assured throughout the operational envelope of the aircraft. For the compression system, this results in the requirement of stall free operation at any possible flow condition. Today's compressors are designed with an adequate stall margin to meet this requirement. At the engineering stage, stall margin stack-ups are used where different effects such as transient operating line excursion, inlet distortion and tip clearances are taken into account. The stall margin requirement limits the exploitable performance of a compressor in terms of pressure ratio, efficiency, and engine dynamics. Various active control concepts to allow safe operation of the engine with reduced stall margins, and to increase efficiency by reducing clearance and avoiding flow separation are currently being researched. These are briefly discussed in the following.

\section{Active Stall Control}

Active stall control offers two major advantages for a gas turbine. A direct benefit is given by the enhanced stability of the compressor. This additional margin may be used to close existing lack of stability or to tighten operability requirements through quicker engine acceleration and deceleration or additional allowances for inlet distortion. An additional benefit can be gained by addressing the compressor design. If parts of the stall margin stack up could be provided by active systems only if required, the basic stack up would allow for lower incremental stall margin. This would release new design 


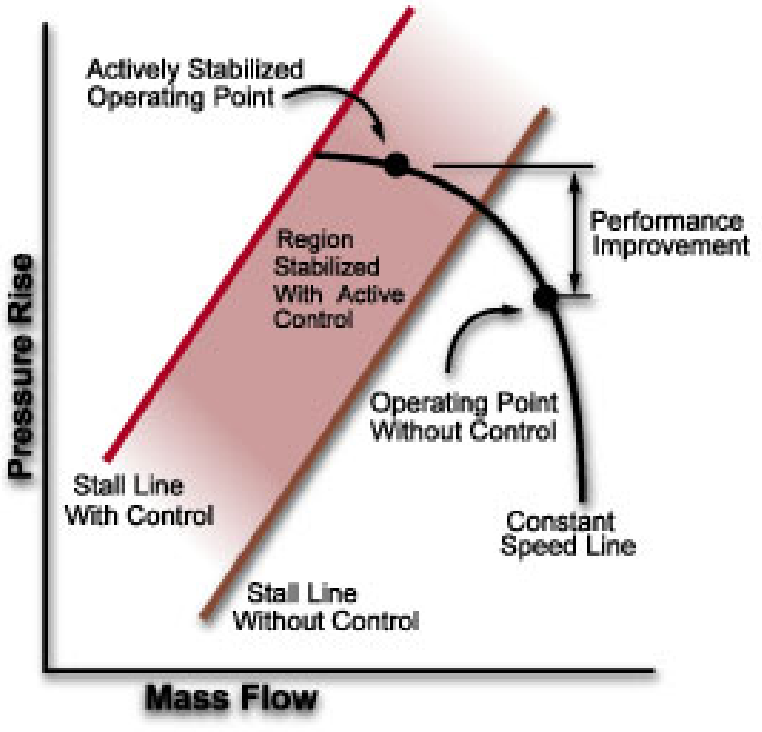

Figure 2.-Enhanced compressor operating point by active stall control.

space which can be used to optimize overall performance, component efficiency and parts count (airfoils or stages) and thus production and maintenance costs. The active stall control concept is shown in Figure 2.

The general feasibility of stall control has been proven in different compressor and engine demonstrators. The basic principle goes back to the possibility of detecting the flow conditions close to the compressor stall point and counteracting by blowing, guide vane movement or dethrottling. When approaching the stall point, a compressor develops stall precursors: high frequency pressure and velocity fluctuations which can be measured by pressure probes or hot wire sensors. The fluctuations occur as modal waves or pressure spikes. The time between the measured precursor and the stall or surge event depends on the aerodynamic nature of the phenomenon. The time delay between the first occurrence of a stall precursor and the stall event is in the order of a few milliseconds. Therefore, it is very challenging to measure and react on a characteristic unsteady disturbance which leads to a compressor stall. Additionally, the kind of unsteady event is very dependent on the actual compressor design and not directly transferable for different compressor designs.

Based on the detected stall condition, different possibilities of counteracting and extending the stable operating range have been proposed. One of the promising technologies consists of injecting high velocity air through discrete holes in the casing into the tip gap of the compressor blade. The feasibility of extending the operating range by tip injection has been demonstrated in several compressor rigs as well as in complete engines (Refs. 8 and 9 for example). Other approaches to stall control consist of high frequency control of variable guide vanes and use of fast actuating bleed valves to stabilize the compression system.

\section{Active Flow Control}

Passive flow control has been used in the compression systems to improve the aerodynamics during off-design operation of a subcomponent. However, these devices decrease aerodynamic performance during operation at design condition. A better approach consists in a fully controlled application of flow control which is only deployed when needed. Example applications of active flow control for compressors are described in References 10 and 11. Some of the active flow control techniques currently under investigation include: transpirated and aspirated compressor airfoil and annulus; pulsed jets including zero-mass-flow devices (aka Synthetic Jets); micro-sized flow actuation devices; airfoil morphing and vortex generators.

The typical sensed variable for active flow control is static pressure. However, the measurement of other physical properties like velocity gradients or shear stresses is sometimes more appropriate to describe internal conditions of a fluid flow. The introduction of optical measurement techniques (laser or infrared diodes) is advisable due to their non-destructive measurement principle. The development of advanced sensors can improve the prediction capability significantly, e.g. a shear stress sensor can identify a flow separation more reliable then a pressure sensor.

\section{Active Clearance Control}

Clearances represent one of the basic problems in turbomachinery as they have a negative impact on efficiency. In the compressor especially, radial blade tip clearances have a detrimental effect on component performance and stability. Active clearance control (ACC) helps to maintain stability and efficiency by maintaining optimized radial clearances throughout the whole operating range of the compressor. In conventional design, the thermal behavior of the compressor often is adapted by adding weight to the casing. Presently available systems are based on the thermal expansion of the casing, which can be controlled by modulating cooling air. The amount of cooling air is scheduled over an operating parameter, such as corrected speed or pressure ratio. Current ACC systems are not able to compensate transient clearance changes because of the thermal inertia of the casing and the missing link between actual clearances and amount of cooling air.

Innovative ACC systems are designed as closed-loop systems. By measuring the actual blade tip clearance a signal can be generated which is fed into an actuator. The actuator adjusts the position of the casing, modifying clearance to an optimum value. The actuator may be designed as a thermal, mechanical or pneumatic acting system (Ref. 12). The main advantages of advanced clearance control systems are given by the capability to react on any clearance change and thus counteracting deterioration and transient effects. This improves 
the component efficiency, not only for a new engine with lower incremental margins but also for a deteriorated engine by keeping optimum clearances over the engine life.
Based on the above discussion, the sensor and actuator requirements for active control of compression system are summarized in Table 2.

TABLE 2.-SENSOR AND ACTUATOR REQUIREMENTS FOR ACTIVE FAN AND COMPRESSOR CONTROL

\begin{tabular}{|c|c|c|c|c|}
\hline Technology & $\begin{array}{c}\text { Sensed } \\
\text { variable }\end{array}$ & Sensor requirements & $\begin{array}{c}\text { Controlled } \\
\text { variable }\end{array}$ & Actuator requirements \\
\hline $\begin{array}{l}\text { Active flow } \\
\text { control }\end{array}$ & \begin{tabular}{|l|} 
Static \\
pressure
\end{tabular} & $\begin{array}{l}\text { - } 35 \mathrm{kPa} \text { dynamic range } \\
\text { - } \pm 0.5 \% \text { resolution } \\
\text { - } 20 \mathrm{~Hz} \text { to } 100 \mathrm{kHz} \\
\text { bandwidth for sensors } \\
\text { (depending of the flow } \\
\text { phenomena measured) }\end{array}$ & $\begin{array}{l}\text { - Jet (pulsed, zero- } \\
\text { net-mass-flow), } \\
\text { suction, blowing, } \\
\text { airfoil geometry } \\
\text { change }\end{array}$ & $\begin{array}{l}\text { - Fluidic actuation devices installed in airfoil at different } \\
\text { frequency ranges: } \\
\text { - } 200 \text { to } 300 \mathrm{~Hz} \text {, } \\
\text { - } 500 \mathrm{~Hz} \text { to } 5 \mathrm{kHz} \\
\text { - } 50 \text { to } 100 \mathrm{kHz} \\
\text { - Steady blowing of < } \% \text { core flow at } 1 \text { to } 2 \mathrm{~Hz} \\
\text { - Shape memory alloys installed in airfoil for shape variation } \\
\text { - Deployable within few seconds }\end{array}$ \\
\hline
\end{tabular}

\section{Active Combustion Control}

The three main areas of interest in the active control of aircraft engine combustion systems are: pattern factor control, emission minimizing control and combustion instability control. Of these, combustion instability control is the most challenging and is discussed in a little more detail below, followed by a brief discussion of the other two approaches.

\section{Combustion Instability Control}

As the requirements for reducing emissions become more stringent, the combustor designs move toward a "lean" burning solution where the fuel/air mixture is richer in air to allow for complete combustion of the fuel. The lowest level of NOx (nitrogen oxides) emissions for gas turbines can be achieved by employing lean combustion strategy at low flame temperature. However, as the fuel-air ratio approaches the lean blow-out (LBO) limit, the flame temperature will not support sufficiently fast CO (carbon monoxide) oxidation rates and its concentration in the combustor exhaust increases. There is a "window" of fuel/air ratio, and of corresponding flame temperature, that will simultaneously result in low NOx and CO. However thermoacoustic instabilities in these regimes are commonly observed and pose a development challenge. Active control of such oscillations will allow for more efficient combustor designs.

Active combustion instability control (AIC) manipulates combustion behavior using a dynamic hardware component (actuator) that rapidly modifies an input into the combustion process. In closed-loop control, a sensor is monitoring the combustor output in real time to determine actuator action via control algorithms. Initial AIC combustor experiments were motivated to control combustion instabilities in aero engine augmenters. More recently the instability control has been focused on very-low emissions stationary gas turbines and will become critical for future aero engines with operation near lean blow-out limits. AIC generally focuses on combustion dynamics with high bandwidth actuation, typical in the 100 to $1000 \mathrm{~Hz}$ frequency range.

Despite the success of AIC implementation in surface power gas turbines, challenges remain for AIC implementation in aero-engines. These challenges include development of light and reliable actuators, efficient and safe control authority of the actuators on the combustion process, and robust control algorithms. A practical AIC system for mitigation of combustion instabilities in a lean, premixed single-nozzle combustor was demonstrated by United Technologies Research Center (UTRC) at realistic operating conditions (Ref. 13). A single-nozzle combustor, which replicated longitudinal combustion instabilities in an aero engine, was also used by NASA (Ref. 14). Two adaptive control algorithms were successfully evaluated against a simplified simulation of combustion instability, a physicsbased model, and in the combustor rig. 
Conventional sensors for AIC typically include piezoresistive-type or piezoelectric-type transducers for pressure measurements, and photodiodes and photomultipliers to provide information on chemiluminescence and heat release. Current sensors provide global and line-of-sight information. Future sensors, which would determine localized conditions, will benefit active control (for example local flame blow-out sensors and local fuel/air ration sensors).

Challenges remain for scale-up with liquid fuel modulation, where time delays increase with liquid fuel atomization, droplet heating, vaporization, and combustion. The current actuator limits in amplitude, rate, and bandwidth will become even more severe in future applications as AIC requirements move to higher frequencies. For the NASA single-nozzle combustion rig, Georgia Tech developed a magnetostrictive actuator that is connected to a pintle-type injector. Other AIC actuators that have been developed include: (1) compression drivers that add acoustic energy at particular frequencies; (2) flow injectors that add secondary mass flux at a particular timing; (3) mechanical devices, piezoelectric actuators, and pulsed air jets that either trip the transient boundary layers or change the shear layer mixing; (4) pulsed-combustion actuators that generate periodic heat release and sound waves; and (5) moving surfaces that create local disturbances.

\section{Emission Control}

For a given combustor design, it is possible to reduce the NOx emission through active control of the fuel/air mixture. The challenges for this technology are development of emission sensors for the harsh engine environment, development of simplified NOx production models that can be used for control design, and determining the most suitable approach to actively control the fuel/air mixture ratio.

\section{Pattern Factor Control}

The Burner Pattern Factor is defined as the ratio of the difference between the maximum and average temperature at the turbine inlet to the average temperature at the turbine inlet. Reducing the burner pattern factor through active control will allow for more efficient fuel burning, decreased emissions and increased life of turbine blades. The biggest challenge here is getting reliable long life sensors to measure temperature in a high temperature environment. The actuation challenge is to provide independent fuel modulation for each fuel injector.

Based on the above discussion, the sensor and actuator requirements for Active Combustion Control are summarized in Table 3.

TABLE 3.-SENSOR AND ACTUATOR REQUIREMENTS FOR ACTIVE COMBUSTION CONTROL

\begin{tabular}{|c|c|c|c|c|}
\hline Technology & $\begin{array}{c}\text { Sensed } \\
\text { variable }\end{array}$ & Sensor requirements & $\begin{array}{c}\text { Controlled } \\
\text { variable }\end{array}$ & Actuator requirements \\
\hline $\begin{array}{l}\text { Emission } \\
\text { control }\end{array}$ & $\begin{array}{l}\text { emissions } \\
(\mathrm{CO}, \mathrm{NOx})\end{array}$ & $\begin{array}{l}\bullet \pm 5 \% \text { accuracy } \\
\bullet<5 \text { Hz bandwidth } \\
\text { - Installation in HPT }\end{array}$ & $\begin{array}{l}\text { - Fuel flow } \\
\text { actuation }\end{array}$ & $\begin{array}{l}\text { - Schedule on emission sensing } \\
\text { - } 5 \text { to } 10 \% \text { of total fuel flow modulated at } 0.1 \text { to } \\
1 \mathrm{~Hz}\end{array}$ \\
\hline
\end{tabular}

\section{Active Turbine Control}

Modern aero engine turbines are designed and optimized with respect to several main targets. As turbine efficiency has a strong impact on the thermodynamic cycle, the component efficiency plays an important role for the optimization of fuel burn and emissions. Increased turbine efficiency is characterized by large flow turning angles and high pressure gradients. Separation bubbles occur on the airfoil surfaces causing losses and limiting the design space. Another important source of losses are the tip clearances. Overtip leakage does not contribute to turbine work and causes strong vortices at the blade tips. As the cycle efficiency increases with temperature, the trend in modern gas turbines goes towards very high turbine inlet temperatures. Current inlet temperatures are beyond tolerable material temperatures, so strong cooling is required. If the cooling flow is injected behind the first stator vane throat, it will reduce the cycle efficiency to a large extent. Turbine capacity is another important parameter for engine operation, as it limits the flow through the gas turbine and controls the compressor working line.

\section{Active Turbine Tip Clearance Control}

The radial gap between the casing and the rotating parts of a turbine (i.e. blade tips or shroud) causes aerodynamic losses which negatively affect gas turbine performance. Opening this gap yields a decrease in turbine efficiency leading to an increase in thrust specific fuel consumption (TSFC). Tip clearance varies with rotor speed due to centrifugal forces and gas conditions such as temperature and pressure. Tip clearance changes during transient maneuvers due to the thermal behavior of the turbine components rotor, blades and casing. During an acceleration, for example, the rotor speed increases 
leading to a closure of tip clearance. The gas temperature increases and heats up the turbine components, wherein the blades heat up quickly due to their low mass and full contact to the gas while the casing heats up much slower. This results in the condition of least tip clearance within a flight mission, which is called "pinch point". The difference in thermal behavior of the components leads to tip clearance variations with time even after the demanded rotor speed has been reached. With respect to a safe engine operation, the cold build clearance is designed for minimized tip clearances on one hand, but also for rub avoidance between blades and the casing in all situations within a mission. However, every operating point besides the pinch point features a larger clearance and therefore lower efficiency. Passive clearance control systems modify thermal behavior with different materials, insulation techniques, etc, but these devices are not capable of compensating clearance variations due to speed changes. In order to minimize tip clearance during different operating conditions, active clearance control (ACC) should be incorporated.

Most modern engines feature a thermal turbine ACC-system, which is state of the art technology. By applying cooling air onto the supporting structure of the turbine, the radial position of the casing can be modified in order to minimize tip clearance by thermal expansion. This technology's benefit is mostly exploited during cruise operation for commercial aircraft. However, thermal ACC-systems are relatively slow, so they cannot react to quick speed changes, which must be considered in the amount of cooling air supplied onto the casing. Provision of additional clearance is necessary to allow engine acceleration without rub-in.

A possibility to overcome the delay of the casing adjustment is to position it mechanically rather than thermally. NASA has investigated different mechanical actuation systems for the high pressure turbine (Ref. 15). Most sophisticated concepts for a mechanical ACC system use electrical or hydraulic actuation mechanisms with mechanical transmission. Other actuation concepts based on piezo-electric movement or shape memory alloys are promising but need further development. Closed-loop control laws incorporate a tip clearance sensor, giving a signal to the control unit, based on which the ACC actuator adapts its position. In principle, such closed-loop controls can detect any kind of clearance variation (symmetric, asymmetric, deterioration) and react quickly (if in use with a mechanical actuation system) (Ref. 16). However, turbine tip clearance sensors have to meet high demands on accuracy and must operate successfully in a high temperature, high vibration environment with contaminated air.

\section{Film Cooling Flow Control}

Structures in the hot section of a gas turbine need to be cooled by air flows to provide sufficient durability. As cooling air flows represent a loss for the thermodynamic cycle, their amount needs to be optimized. Film-cooling of gas turbine vanes is the current approach to maintaining turbine durability in the hot engine environment. The effectiveness of this approach depends on the extent to which the cool jet-fluid adheres to the cooled component surface. Lift-off of the cooling jet flow, or other mechanisms promoting mixing, cause loss of cooling effectiveness as they allow the hot "freestream" fluid to come in contact with the component surface. The cooling effectiveness can be improved by actively controlling the jet flow in a manner such as to prevent/delay lift-off and suppress mixing. Furthermore, an actively controlled film-cooling system coupled with appropriate sensory input (e.g. temperature or heat flux) can adapt to spatial and temporal variations of the hot gas path. Thus, it is conceivable that the efficiency of film-cooling systems can be further improved by intelligently directing the flow where it is most needed. Because of the small passages for the flow, it is envisioned that MEMS (Micro Electro-Mechanical Systems) technology will be critical to develop the enabling actuation system for active control of turbine film-cooling (Ref. 17).

\section{Cooling Air Control}

For state of the art core engines, about 20 to 30 percent of the air delivered by the HPC (High Pressure Compressor) is used for cooling the HPT (High Pressure Turbine), thus "bypassing" the cycle and having further detrimental effects on the core. For engines currently in service, the cooling air flow path is fixed and the cooling air is "hot" compressor discharge air. If the supplied air flow is cooled by a heat exchanger, colder turbine metal temperatures can be achieved. As a result, the amount of cooling air can be reduced or the turbine inlet temperature increased. Both directions lead to an improved gas turbine cycle.

Based on the above discussion, the actuator and sensor requirements for active turbine control are summarized in Table 4.

\section{Active Nozzle Control}

The areas to be considered for active nozzle control include actively reducing the exhaust noise, thrust vectoring control using mechanical or fluidic actuation, and afterburner stability control.

\section{Active Noise Control}

The reduction of aircraft noise continues to be the subject of considerable effort. Much of the effort has been on advancing noise reduction technologies where they can be turned on and off or even change geometry of the various components. The reason for this is that the noise reduction technologies almost always result in some loss of performance to the aircraft engine. If technologies can be developed that can be turned off when noise reduction is not needed, then there could be a system benefit to the aircraft. Two of the specific technologies that have been under investigation are variable geometry chevron nozzles and fluidic injection. Flight testing has demonstrated the effectiveness of serrations (chevron nozzles) for noise reduction, but also confirmed the expected 
TABLE 4.-SENSOR AND ACTUATOR REQUIREMENTS FOR ACTIVE TURBINE CONTROL

\begin{tabular}{|c|c|c|c|c|}
\hline Technology & Sensed variable & Sensor requirements & Controlled variable & Actuator requirements \\
\hline $\begin{array}{l}\text { Active clearance } \\
\text { control }\end{array}$ & Clearance & $\begin{array}{l}\text { - } 2.5 \mathrm{~mm} \text { range, } \\
\text { - } \text { Accuracy } \pm 25 \mu \mathrm{m} \\
\text { - } 50 \mathrm{kHz} \text { bandwidth } \\
\text { - Case-mounted installation }\end{array}$ & - Casing geometry & $\begin{array}{l}\text { - Thermal, mechanical, pneumatic devices } \\
\text { - Actuation rate }>0.1 \mathrm{~mm} / \mathrm{s} \text { bandwidth } 1 \text { to } \\
5 \mathrm{~Hz} \\
\text { - Force } 10 \mathrm{kN} \\
\text { - Stroke } 3 \mathrm{~mm} \\
\text { - Resolution } 0.02 \mathrm{~mm}\end{array}$ \\
\hline $\begin{array}{l}\text { Film cooling flow } \\
\text { control }\end{array}$ & Static pressure & $\begin{array}{l}\text { - Equivalent to compressor flow } \\
\text { control } \\
\text { - Steady flow control may be } \\
\text { based on operating point. }\end{array}$ & $\begin{array}{l}\text { - Jets, boundary layer } \\
\text { suction, plasma } \\
\text { actuator }\end{array}$ & $\begin{array}{l}\text { - Plasma actuator bandwidth } 10 \text { to } 200 \mathrm{~Hz} \\
\text { at } 5 \mathrm{kHz} \text {, voltage } 5 \text { to } 25 \mathrm{kV} \\
\text { - Steady blowing }<0.1 \% \text { of core flow }\end{array}$ \\
\hline $\begin{array}{l}\text { Cooling air } \\
\text { control }\end{array}$ & \begin{tabular}{|l|} 
Surface \\
temperature \\
turbine stator \\
blade
\end{tabular} & $\begin{array}{l}\text { - } \text { Min resolution } \pm 5^{\circ} \\
\text { - Steady state, } 1 \mathrm{~Hz}\end{array}$ & $\begin{array}{l}\text { - } \text { Total flow } \\
\text { modulation or } \\
\text { - Individual blade flow } \\
\text { modulation }\end{array}$ & $\begin{array}{l}\text { - } 1 \mathrm{~Hz} \text { bandwidth } \\
\text { - } 20 \% \text { modulation of baseline cooling flow }\end{array}$ \\
\hline
\end{tabular}

performance penalty (Ref. 18). Since noise reduction is only needed at very low altitude, work has been ongoing to implement shape memory alloy materials (SMA) in chevron nozzles for the outer nacelle of an aircraft engine, which will withdraw the serrations at altitude.

Shape memory alloys have the unique characteristic that they can be trained to change shape at a specific temperature. Thus, for take-off, the chevron nozzle can be one shape and then once out of noise sensitive regions, they can be another for aerodynamically efficient shape. The primary challenge is to produce an SMA based system that would be capable of providing sufficient operational stiffness and high movement whilst still being cost effective and safe (Ref. 19).

Fluidic injection started as a way to avoid mechanical chevrons and get the same fluid dynamic effect with injected flow. Again, this has the advantage that it can be turned off when not needed (Ref. 20).

\section{Thrust Vectoring}

Mechanical thrust vectoring is already available in currently operational fighters. The replacement of the current mechanical systems with a fluidic approach has various potential benefits, such as weight reduction and reliability advantages. Computational and reduced scale experimental studies jointly performed by airframe and engine manufacturers have demonstrated the potential of fluidic actuation in throat area control of the nozzles of afterburning engines and also for thrust vector control, either for enhanced agility of combat aircraft or in future unmanned vehicles, to potentially reduce the need for moving aerodynamic control surfaces. By fluidic skewing of the nozzle throat, effective thrust vectoring can be accomplished. However the amount of air flow to control flow direction is around 1 percent of injected flow for every $1.5^{\circ}$ of vector angle (Ref. 21), which would have to be considered in the overall performance cycle of the engine.

\section{Afterburner Stability Control}

It is well known that current augmented military jet engines have the potential problem of instabilities of the exhaust jet during afterburner operation. Basically, there are two forms of instability: Axial, low frequency (buzz, rumble); and Radial, high frequency (screech). The existing stability control systems monitor certain frequency bands of the dynamic pressure $(<100 \mathrm{~Hz}$ for longitudinal instability, $>500 \mathrm{~Hz}$ for radial instability). When any of these stabilities is detected, current practice is to cut afterburner fuel flow and to actuate (open) the nozzle. The existing identification methods have to be improved in order to avoid false alarms. More intelligent sensors could improve the effectiveness of incident detection. Alternatives to piezo-electric sensors have to be investigated. Suppression of instabilities by active control using pulsed fuel injection is being investigated and is somewhat analogous to the application for combustor instability control discussed earlier.

Based on the above discussion, the sensor and actuator requirements for active nozzle control are summarized in Table 5.

\section{Intelligent Control and Health Monitoring}

Reference 22 provides an overall summary of the state-ofthe-art of engine control and health monitoring. Typical aircraft engine control systems maintain fan speed or engine pressure ratio to regulate thrust which is not directly measurable. The control logic is generally based on a variant of a ProportionalIntegral scheme combined with limit logic which selects a fuel flow rate command based on various physical limits, acceleration/deceleration schedules (maximum rotor speed rate-of-change as a function of rotor speed), and the current operating state (speed governor loops). The various on-wing health monitoring systems of today, which are a collection of separate, unrelated technologies, provide a basic level of monitoring. Their capabilities are relatively limited and the 
TABLE 5.-SENSOR AND ACTUATOR REQUIREMENTS FOR ACTIVE NOZZLE CONTROL

\begin{tabular}{|l|l|l|l|l|}
\hline \multicolumn{1}{|c|}{ Technology } & Sensed variable & \multicolumn{1}{|c|}{ Sensor requirements } & Controlled variable & \multicolumn{1}{c|}{ Actuator requirements } \\
\hline $\begin{array}{l}\text { Active noise } \\
\text { control }\end{array}$ & No sensor & $\bullet$ N/A & $\begin{array}{l}\text { Variable nozzle } \\
\text { geometry, jets }\end{array}$ & $\begin{array}{l}\bullet \text { Shape memory alloys } 30 \mathrm{~mm} \text { actuation, } \\
\text { stiffness }<1 \mathrm{~mm} \text { deflection } \\
\text { Pulsed jets } \sim 1 \text { to } 4 \mathrm{kHz}, 0.6^{*} \text { exhaust } \\
\text { velocity, } 1 \% \text { engine flow }\end{array}$ \\
\hline $\begin{array}{l}\text { Thrust } \\
\text { vectoring }\end{array}$ & Jet direction & $\begin{array}{l}\bullet \text { Reaction force, optical position } \\
\text { detection? }\end{array}$ & $\bullet$ Nozzle geometry, jets & $\bullet 1.5 \%$ of core flow $/ 1.5^{\circ}$ of vector angle. \\
\hline $\begin{array}{l}\text { Afterburner } \\
\text { stability } \\
\text { control }\end{array}$ & $\begin{array}{l}\text { Dynamic } \\
\text { pressure }\end{array}$ & $\begin{array}{l}\text { 40 to } 800 \mathrm{kPa} \text { static, } \pm 35 \mathrm{kPa} \\
\text { dynamic range, } 20 \mathrm{~Hz} \text { to } 10 \mathrm{kHz}, \\
220 \text { to } 650{ }^{\circ} \mathrm{K}\end{array}$ & $\begin{array}{l}\text { Nozzle geometry / area } \\
\text { fuel flow actuation }\end{array}$ & $\bullet$ Existing afterburner actuators \\
\hline
\end{tabular}

information they provide is used mostly to initiate maintenance actions, not for real-time decision-making. While these traditional control and diagnostic techniques are timetested and reliable, advanced techniques provide the promise to meet the challenging requirements of improved fuel efficiency, increased durability and life, decreased life cycle costs, and improved operations. Using an on-board engine model to meet the challenging control and diagnostics requirements has emerged as the most viable approach.

The concept of model-based control and diagnostics is shown in Figure 3. The engine model is driven with the measured engine inputs (shown here as control signals, u, but usually also includes environmental conditions) to obtain the predicted engine sensor outputs $\hat{y}$. The predicted outputs are differenced with the measured engine sensor outputs, $y$, to form residuals, which can be used to diagnose engine health and adapt the model.

One of the major challenges in implementation of modelbased control and diagnostics is to have the model reflect the actual condition of the engine. Historically a single, fleet average model is used based on known or expected fleet average performance of a particular engine type. Use of this average model to predict individual engine performance within a fleet results in varying model errors, corresponding to how each engine deviates from the average. The resulting model error couples with normal flight variations in the input conditions to cause systematic error in the residuals, which limits the capability of the model to accurately predict the

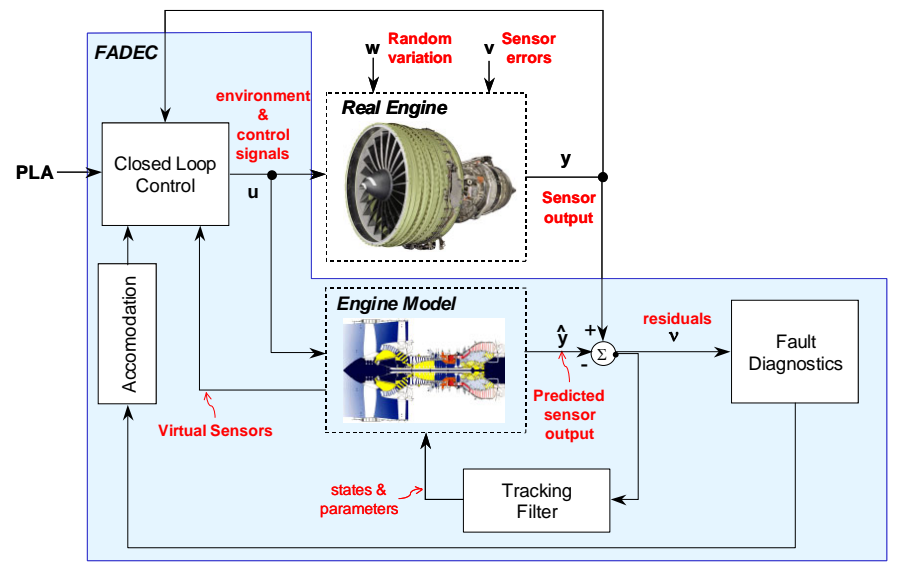

Figure 3.-Model-based control and diagnostics concept. unmeasured variables. Also, when a fault occurs in the engine, if this fault is not appropriately reflected in the model, it can cause significant errors in estimation of the unmeasured variables. Thus, it is important to ensure that the model being used for control reflects the true condition of the engine. Typically a "tracking filter" is used to estimate model parameters related to deterioration causing the model to "track" the individual engine over time. Since the accuracy of the estimates based on the tracking filter is a function of the available sensors, the effectiveness of model based control can be improved if appropriate additional sensors are available.

In this model-based structure, the model can provide outputs for which there is no sensor, i.e. virtual sensors. These virtual sensors provide the capability to directly control unmeasured variables such as thrust and stall margin. Additionally, the model outputs can be used for sensor fault accommodation, where model output (predicted sensor reading) temporarily replaces a failed sensor, and virtual duplex redundancy, where the model output permanently replaces one sensor in a duplex pair. Also, the tracked parameters can be monitored to provide an indication of the health of the components of the engine, e.g. the level of deterioration in health parameters such as component efficiency. Typically, abrupt faults are detected with the diagnostics algorithm and slowly changing health assessed by monitoring these tracked parameters. References 23 to 27 discuss various approaches for model based control, and fault detection and isolation of aircraft engines. If the effect of the fault on engine operability and/or safety is small, no accommodation is required and the diagnostics information can be used to schedule maintenance. However, if the fault has an appreciable effect, then accommodation can potentially avoid in-flight shut downs, stalls, excessive life consumption, etc. (Refs. 28 and 29).

\section{Challenges and Sensor Needs}

Challenges exist in several areas in implementing the technologies described above. The models must be computationally efficient in order to run in real time without sacrificing accuracy. However, model error is difficult to quantify because it must be evaluated in closed loop (i.e. with the tracking filter) which couples it with the choice of tracked parameters and their observability with the given sensor suite. 
This creates a sensor paradigm shift where sensors are chosen not only for direct control purposes but also for model accuracy (Ref. 30). Equally important is the fault model or signature as it limits the sensitivity of fault detection. Finally, the increased complexity brings certification and maintenance challenges. Any engine models used inside the control loops will need to be certified. The complexity of the models and adaptive nature of the tracking filter adds to the challenge.

Typical gas path sensors consist of temperature, pressure and rotor speed measurements. Any improvements in the accuracy, uniformity and reliability of these gas path sensors will result in a direct improvement in the accuracy of performance diagnostics and model-based control technologies. Also, there are currently stations within the engine gas path that are not instrumented due in part to the harsh operating temperatures that exist at these locations. Measurements at these additional locations will further enhance the accuracy of gas path analysis techniques. In addition to conventional gas path pressure and temperature measurements, the ability to sense additional parameters would be beneficial in diagnosing engine performance faults and providing improved estimate of unmeasured variables such as thrust. For example, gas path debris monitoring sensors for monitoring and quantifying engine debris ingestion and discharge are desirable. Mass flow sensors to estimate the flow through the fan duct and the nozzle will help generate better estimates of the thrust being produced by the engine-especially if there is any damage which results in degraded engine performance. Additional need is in improved fuel flow sensors. These sensor requirements are summarized in Table 6.

TABLE 6.-SENSOR REQUIREMENTS FOR INTELLIGENT CONTROL AND HEALTH MONITORING

\begin{tabular}{|l|l|l|l|}
\hline Component & Technology & Sensed Variable & Sensor Requirements \\
\hline Inlet & Stall margin estimation & Pressure & 0 to 2.5 psi range, $0.25 \%$ accuracy, $500 \mathrm{~Hz}$ bandwidth \\
\hline Fan/compressor & Thrust estimation & Mass Flow & $1.75 \%$ accuracy \\
\hline Fan/compressor & Vibration monitoring & Accelerometer & 1000 g range, $3 \%$ accuracy, $40 \mathrm{kHz}$ \\
\hline Combustor & Thrust estimation & Fuel mass flow & $\pm 0.1 \%$ accuracy \\
\hline Turbine & Clearance management & Clearance & $2.5 \mathrm{~mm}$ range, $25 \mu \mathrm{m}$ accuracy, $50 \mathrm{kHz}$ bandwidth \\
\hline Turbine & $\begin{array}{l}\text { Life management/ } \\
\text { temperature margin }\end{array}$ & Temperature & $\begin{array}{l}\text { T41, T48, } 5^{\circ} \text { accuracy, } 2 \text { to } 10 \mathrm{~Hz}, \text { flow and blade } \\
\text { temperature }\end{array}$ \\
\hline Nozzle & Exhaust debris monitoring & Exhaust gas composition & $1 \%$ accuracy \\
\hline
\end{tabular}

\section{Distributed Engine Control}

Presently, engine control system architecture is based on a centralized design in which discrete sensors and effectors are directly wired to an engine-mounted electronics package. This avionics unit, often known as the FADEC (Full Authority Digital Engine Control), contains all the necessary circuitry to properly interface with engine control devices as well as cockpit command and data communications. The design of a centralized engine control system is primarily based on the single overriding concern of minimal control system weight because of its effect on overall vehicle performance. Much of the design is based on legacy, the result of incremental improvement over many years. This constraint severely limits the design choices for avionics engineers. The centralized engine control architecture is shown in Figure 4.

The FADEC houses specific electronics to interface with engine-mounted control elements (sensors and actuators). Dual redundancy is often used which drives up harness weight while connector size drives enclosure dimensions. The large FADEC housing is environmentally hardened, cooled, and colocated on the engine structure. The engine structure is quite a severe environment for an avionics package. Vibration and temperature extremes force the electronics to be custom designed for a specific engine. Circuit components are specifically designed for maximum density to achieve small physical size thereby increasing stiffness and raising the natural frequency of resonant mechanical vibration modes. This adversely affects heat dissipation in the assembly. The large number of conductors and the physical size of the connector shells mounted on the FADEC enclosure often drive the package dimensions. The entire package must be mounted on low frequency isolators to reduce the shock loads experienced over a mission profile. Temperature extremes at the engine structure require cooling to reduce the operating temperature of semiconductor junctions to an acceptable level. This is maintained by conduction cooling the entire assembly with a cold plate using the aircraft fuel supply as the heat removal media.

Under a centralized engine control system architecture, the need to reduce overall weight drives a chain of design constraints which result in an optimized engine control system, but one which is costly to both procure and maintain. Furthermore, because it is so highly optimized, it is inflexible to use in multiple platforms or even to accommodate upgrades in an existing application. Changing the engine control architecture to a distributed system can radically alter the interrelated chain of constraints which ultimately drive overall cost of ownership. 


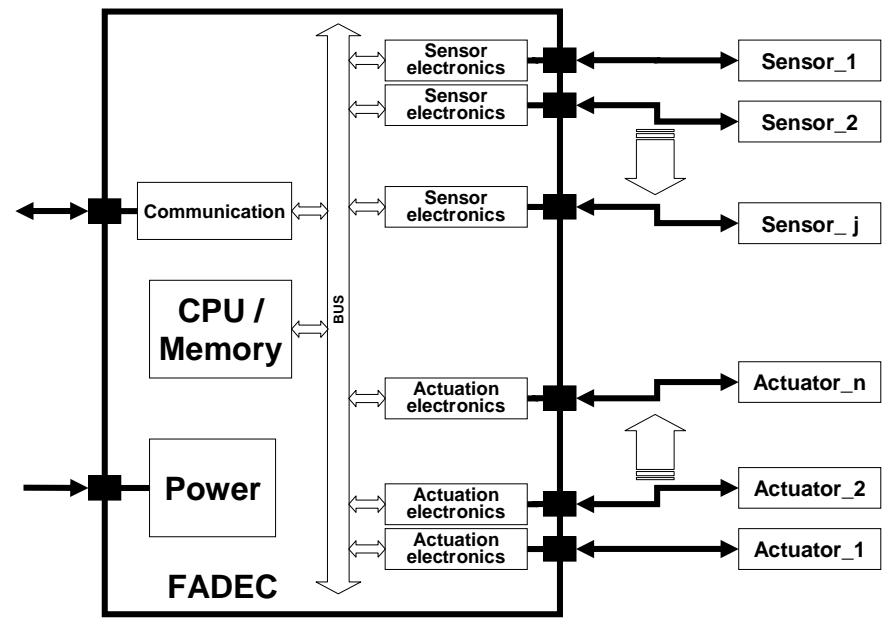

Figure 4.-Centralized engine control architecture.

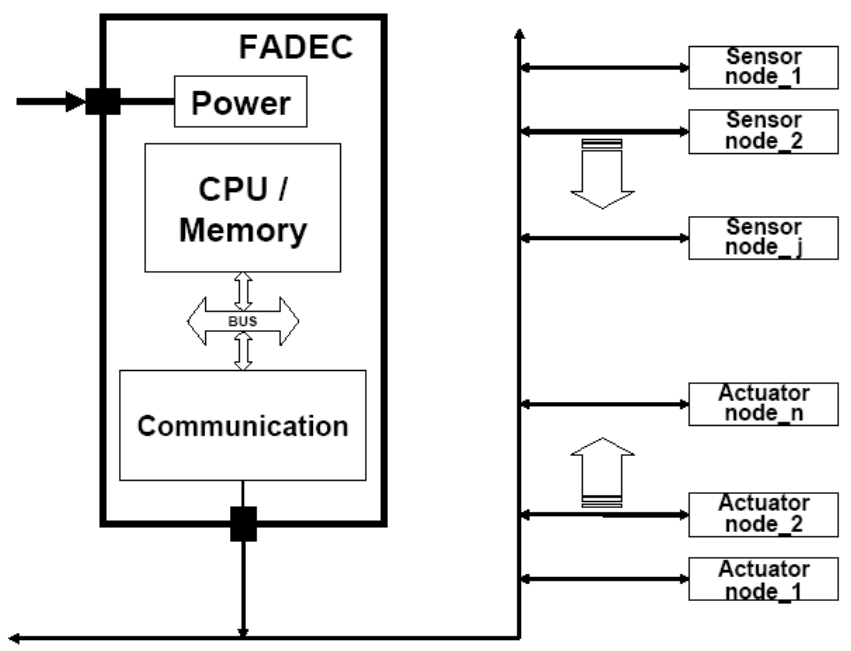

Figure 5.-Distributed engine control architecture.

In a distributed engine control system architecture, as shown in Figure 5, any number of control elements are tied together through a common, standardized, communication interface. Sensors and actuator electronics are removed from the FADEC and are replaced by control nodes which may provide sensor data, operate actuators, or perform combinations of both. The massive wiring harness which previously tied together the control element to interface circuitry in the engine-mounted avionics package is replaced by a simple but robust communication structure. Weight reduction is the primary motivation but the standardized interface is also an enabling feature which is necessary to effectively implement future active and adaptive control applications (Ref. 31).

In a distributed engine control architecture, weight optimization no longer drives the design and packaging of the
FADEC. This leads to broad cross platform standardization and significant cost reductions in both acquisition and maintenance. The issue of system upgrade becomes one largely focused on software re-qualification instead of complete system re-qualification.

NASA Glenn Research Center in conjunction with members of the U.S. Department of Defense and the U.S. Aerospace industry has established a Distributed Engine Control Working Group (DECWG) to examine the current and future technology requirements to enable distributed control for aircraft engines. The work of this group to date in terms of assessing the paradigm shift from centralized engine control architecture to an architecture based on distributed control using open system standards is summarized in Reference 32.

It is important to note that no new sensors or actuators are needed to enable distributed engine control. What is needed is to have on-board electronics located on or close to the sensing element or the actuator effector such that network communications can be enabled and the wiring harness required for communications between sensors and actuators and the engine controller can be substantially reduced. Another challenge for enabling distributed engine control is to supply the power needed for the on-board electronicsinnovative power supply architectures and technologies will need to be developed to exploit the full potential benefits of distributed engine control.

\section{Universal Sensor and Actuator Requirements}

The previous sections have focused on the requirements for sensors and actuators for "More Intelligent Gas Turbine Engines" from the perspective of performance and operating environment. Even if a technology is available, which meets these performance requirements, there are still various hurdles to be overcome for the technology to transition into a real engine. Such requirements relate to TRL (Technology Readiness Level), durability, reliability, volume, weight, cost etc. This section provides an overview of such universal requirements which any sensor or actuator technology will have to meet before it can be implemented on a product. The objective here is to help educate the researchers or technology developers on the extensive process that the technology has to go through beyond just meeting performance requirements. The hope is that such knowledge will help the technology developers as well as decision makers to prevent wasteful investment in developing solutions to performance requirements, which have no potential to meet the "universal" requirements. These "universal" requirements can be divided into 2 broad areas: (1) technology maturation and (2) value proposition of the technology. The technology maturation requirements are generally well understood by technology developers. The process of moving a product, process or component towards maturity typically follows the development route as described in the Technology Readiness 
Level (TRL) definitions (Ref. 33). The process typically follows a gated process involving formal reviews at specific stages, generally related to specific TRLs. Business, manufacturing, legislative etc. issues must be covered at an appropriate level at all stages. The technology value proposition is briefly described in the following, since it is not that well understood by technology developers.

\section{Technology Value Proposition}

A fundamental premise (beyond basic safety) for considering the incorporation of any component onto/into the engine is that it adds value. Some components will be considered intrinsic to the engine design and functionality (e.g. engine control, fuel system components, cycle temperature sensors), and as a result, their value is tied directly to the overall product's attributes (fuel burn, range, direct maintenance cost). All other non-intrinsic components added to the engine are required to provide some level of value that, at a minimum, mitigates the negative effects of its installation (weight, volume, energy consumption, installed losses). In the best case, the value added will provide direct positive impact to the customer in terms of increased revenue opportunities, or via easily measured life-cycle cost reductions.

One common way that value analysis is performed is via a calculation of customer net present value (NPV). This common metric allows for capture of the life cycle costs and benefits of the proposed component or feature. Typical evaluation elements include (but are not limited to) the following:

\section{Impact on Revenue}

Does the technology provide enhanced utilization rates, increased dispatch reliability, increased ETOPS (Extendedrange Twin-engine Operational Performance Standards) availability, or performance improvement? Is the technology a performance enabler?

\section{Impact on Cost}

How much will the cost of the engine go up if the technology were to be incorporated into the engine? What will be the overall impact of the technology on the life cycle cost of the engine in terms of labor and time cost associated with part removal, line maintenance, shop maintenance, repair, troubleshooting, etc.

\section{Other}

Other than revenue and cost, some other factors to be considered for sensors and actuators are impact on overall engine weight, the capability of the technology to fit into the specified volume (since real estate on an engine is at a premium), accessibility once installed onto/into the engine, cooling requirements, power and wiring requirements etc. Designing for ease of integration into the engine has to be an important element of developing any technology solutions to challenging sensor/actuator performance requirements.

\section{Summary and Recommendations}

Intelligent Gas Turbine Engines (GTE) can potentially meet future challenges related to capability, affordability, safety, and environmental compatibility. The key enabling technologies for an intelligent GTE are (1) increased efficiencies of components through active control, (2) increased overall engine gas-path performance and extended "on wing" life of the engine through model-based control and health monitoring, and (3) reduced weight ratio of control system to engine through distributed control with smart sensors and actuators. An overview of these technologies was provided, and sensor and actuator requirements were identified to achieve these future capabilities. Reference 1 further documents the various sensor and actuator technologies that have the potential to meet these requirements. The concept of more intelligent gas turbine engines should be approached by incremental changes, both by improving existing technology and components and implementing new technologies. Although numerous newly built propulsion systems are already using intelligent components, it is expected that a sustained effort in the implementation of distributed and active control will be attempted, once the technologies identified in this report are developed and demonstrated. A close interaction between the "Customers" and "Researchers and Technology Developers" is needed to optimize investment for meeting challenging performance and implementation-related requirements. Recommendations for sensor and actuator development activities are summarized in Reference 1 to achieve a goal of Technology Readiness Level (TRL) 6 (fully demonstrate engineering feasibility) in the near-term (3 to $5 \mathrm{yr}$ ), mid-term (7 to $10 \mathrm{yr}$ ), and long-term (12 to $15 \mathrm{yr}$ ).

\section{References}

1. Dennis Culley, Sanjay Garg, S.J. Hiller, Wolfgang Horn, Aditya Kumar, H. Kirk Mathews, Hany Moustapha, Hugo Pfoertner, Taylor Rosenfeld, Pavol Rybarik, Klaus Schadow, Ion Stiharu, Daniel E. Viassolo, and John Webster, "More Intelligent Gas Turbine Engines,” RTO-TR-AVT-128, April 2009. Available at: http://www.rta.nato.int/Pubs/RDP.asp?RDP=RTO-TR-AVT-128.

2. Simon et al., "Sensor needs for control and health management of intelligent aircraft engines," NASA/TM-2004-212915.

3. Tagashira et al., "A performance optimization control of variable cycle engines,” AIAA-2003-4984.

4. Calhoun et al., "Feasibility and Benefit Assessment of Some Advanced Controls Technologies within the NASA UEET IPC Project,” ISABE-2003-1057.

5. Greitzer, E.M., 2007, "Some Aerodynamic Problems of Aircraft Engines - Fifty Years After,” ASME Paper GT2007-28364

6. Gorton, S.A., Owens, L.R., Jenkins, L.N., Allan, B.G., "Active Flow Control On A Boundary Layer Ingesting Inlet,” AIAA $2^{\text {nd }}$ Flow Control Conference, AIAA-2004-1203 
7. Remington, P.J., Sutliff, D.L. and Sommerfeldt, S., "Active Control of Low Speed Fan Tonal Noise Using Actuators Mounted in Stator Vanes: Part I Control System Design and Implementation,” AIAA-2003-3191, May 2003

8. Weigl et al., "Active stabilization of rotating stall and surge in a transonic single stage axial compressor," ASME 97-GT-411

9. Leinhos, D.C., et al., "Experiments in Active Stall Control of a Twin-spool Turbofan Engine,” ASME GT-2002-30002, Amsterdam, Netherlands, 2002

10. Hiller, S.J., Hirst, M., Webster, J., Ducloux, O., Pernod, P., Touyeras, A., Garnier, E., Pruvost, M., Wakelam, Ch., Evans, S., "ADVACT - An European Program for Actuation Technology In Future Aero-Engine Control Systems,” AIAA $3^{\text {rd }}$ Flow Control Conference, 2006, AIAA-2006-3511

11. Culley, D.E., Braunscheidel, E.P., Bright M.M., 2005, "Impulsive Injection for Compressor Stator Separation Control," AIAA2005-3633, 41st Joint Propulsion Conference, Tucson, USA

12. Jaw et al., "Experimental results of an active clearance control system for a centrifugal compressor," ASME 97-GT-32.

13. Cohen, J. M., Hibshman, J.R., Proscia, W., Rosfjord, T.J., Wake, B.E., McVey, J.B., Lovett, J., Ondas, M., DeLaat, J., and Breisacher, K., "Longitudinal Mode Aeroengine Combustion Instability: Model and Experiment,” NATO/RTO Spring 2000 Symposium on Active Control Technology for Enhanced Performance Operation Capabilities of Military Aircraft, Land Vehicles and Sea Vehicles, Braunschweig, Germany, (2000).

14. Kopasakis, G., "High Frequency Adaptive Instability Suppression Controls in a Liquid-Fueled Combustor," AIAA $39^{\text {th }}$ Joint Propulsion Conference and Exhibit, Huntsville, AL, July 2003, NASA/TM-2003-212535, AIAA-2003-9581.

15. Steinetz, B.M.; Lattime, S.B.; Taylor, S.; DeCastro, J.A.; Oswald, J.; Melcher, K.J., "Evaluation of an Active Clearance Control System Concept," NASA/TM-2005-213856, AIAA-20053989, 2005.

16. De Castro, J.A., Melcher K.J., 2004, “A Study on the Requirements for Fast Active Turbine Tip Clearance Control Systems," AIAA-2004-4176, 40 ${ }^{\text {th }}$ Joint Propulsion Conference and Exhibit, Ft. Lauderdale, FL, USA.

17. Nikitopoulos D.E., Acharya S., Oertling J., Muldoon F. H., 2006, "On Active Control of Film-Cooling Flows," ASME Turbo Expo GT2006-90951.

18. Webster, J.R., “ Potential Applications for Smart Technologies Within Gas Turbines,” ISABE-2001-1109.

19. Webster, J.R., 2006, "High integrity adaptive SMA components for gas turbine applications,” SPIE Smart conference 2006.
20. Henderson, B.S., Kinzie, K.W., Whitmire, J., and Abeysinghe, A., "The Impact of Fluidic Chevrons on Jet Noise," AIAA-20052888.

21. Lord, W.K., MacMartin, D.G., Tillman, T.G., "Flow Control Opportunities in Gas Turbine Engines”. AIAA-2000-2234, Fluids 2000, Denver, CO, 2000.

22. J.S. Litt et al., "A Survey of Intelligent Control and Health Management Technologies for Aircraft Propulsion Systems," NASA/TM-2005-213622, May 2005.

23. S. Adibhatla, and T. Lewis, "Model-Based Intelligent Digital Engine Control (MoBIDEC)," AIAA-97-3192, 33 ${ }^{\text {rd }}$ Joint Propulsion Conference, 1997.

24. Y.G. Li, "Performance-Analysis-Based Gas Turbine Diagnostics: A Review," Proceedings of the Institution of Mechanical Engineers, Part A: J. Power and Energy, Vol. 216, 2002, pp. 363377.

25. L.A. Urban, "Parameter Selection for Multiple Fault Diagnostics of Gas Turbine Engines,” ASME paper 74-GT-62, Gas Turbine Conference and Products Show, 1974.

26. M.D. Espana, "Sensor Biases Effect on the Estimation Algorithm for Performance Seeking Controllers," Journal of Propulsion and Power, Vol. 10, No. 4, July-August 1994, pp. 527-532.

27. T. Kobayashi and D.L. Simon, "Application of a Bank of Kalman Filters for In-Flight Aircraft Engine Sensor Fault Diagnostics," Paper GT-2003-38550, Proceedings of the ASME Turbo Expo, 2003.

28. C.E. Frankenberger, III, "Survivable Engine Control Algorithm Development (SECAD)," Proceedings of IEEE Aerospace Conference, 2002, Vol. 6, pp. 6-3015-6-3020.

29. M. Wiseman and T-H Guo, "An investigation of life extending control techniques for gas turbine engines," Proceedings of the 2001 American Control Conference, Vol. 5, pp.. 3706-3707.

30. .L. Simon, et al., "Sensor Needs for Control and Health Management of Intelligent Aircraft Engines,” Paper GT200454324, Proceedings of the ASME Turbo Expo, 2004.

31. Culley, Dennis, E., Thomas, Randy; Saus, Joseph, "Concepts for Distributed Engine Control,” NASA/TM-2007-214994, November 2007.

32. Behbahani, Alireza, Culley, Dennis, E., et al., "Status, Vision, and Challenges of an Intelligent Distributed Engine Control Architecture," SAE Paper 2007-01-3859, SAE Aerotech Congress, Los Angeles, California, September 18-20, 2007.

33. DOD, (May 2005), Technology Readiness Assessment (TRA) Deskbook. 


\begin{tabular}{|c|c|c|}
\hline \multicolumn{2}{|c|}{ REPORT DOCUMENTATION PAGE } & $\begin{array}{l}\text { Form Approved } \\
\text { OMB No. 0704-0188 }\end{array}$ \\
\hline \multicolumn{3}{|c|}{ 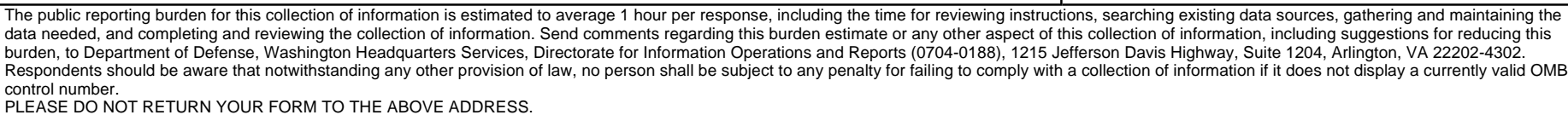 } \\
\hline $\begin{array}{l}\text { 1. REPORT DATE (DD-MM-YYYY) } \\
01-07-2010\end{array}$ & $\begin{array}{l}\text { 2. REPORT TYPE } \\
\text { Technical Memorandum }\end{array}$ & 3. DATES COVERED (From - To) \\
\hline \multirow{3}{*}{\multicolumn{2}{|c|}{$\begin{array}{l}\text { 4. TITLE AND SUBTITLE } \\
\text { Sensor and Actuator Needs for More Intelligent Gas Turbine Engines }\end{array}$}} & 5a. CONTRACT NUMBER \\
\hline & & 5b. GRANT NUMBER \\
\hline & & 5c. PROGRAM ELEMENT NUMBER \\
\hline \multirow{3}{*}{\multicolumn{2}{|c|}{$\begin{array}{l}\text { 6. AUTHOR(S) } \\
\text { Garg, Sanjay; Schadow, Klaus; Horn, Wolfgang; Pfoertner, Hugo; Stiharu, Ion }\end{array}$}} & 5d. PROJECT NUMBER \\
\hline & & 5e. TASK NUMBER \\
\hline & & $\begin{array}{l}\text { 5f. WORK UNIT NUMBER } \\
\text { WBS 736466.08.01.03.03 }\end{array}$ \\
\hline \multicolumn{2}{|c|}{$\begin{array}{l}\text { 7. PERFORMING ORGANIZATION NAME(S) AND ADDRESS(ES) } \\
\text { National Aeronautics and Space Administration } \\
\text { John H. Glenn Research Center at Lewis Field } \\
\text { Cleveland, Ohio 44135-3191 }\end{array}$} & $\begin{array}{l}\text { 8. PERFORMING ORGANIZATION } \\
\text { REPORT NUMBER } \\
\text { E-17323 }\end{array}$ \\
\hline \multirow{2}{*}{\multicolumn{2}{|c|}{$\begin{array}{l}\text { 9. SPONSORING/MONITORING AGENCY NAME(S) AND ADDRESS(ES) } \\
\text { National Aeronautics and Space Administration } \\
\text { Washington, DC 20546-0001 }\end{array}$}} & $\begin{array}{l}\text { 10. SPONSORING/MONITOR'S } \\
\text { ACRONYM(S) } \\
\text { NASA }\end{array}$ \\
\hline & & $\begin{array}{l}\text { 11. SPONSORING/MONITORING } \\
\text { REPORT NUMBER } \\
\text { NASA/TM-2010-216746 }\end{array}$ \\
\hline \multicolumn{3}{|c|}{$\begin{array}{l}\text { 12. DISTRIBUTIONIAVAILABILITY STATEMENT } \\
\text { Unclassified-Unlimited } \\
\text { Subject Categories: } 07 \text { and } 63 \\
\text { Available electronically at http://gltrs.grc.nasa.gov } \\
\text { This publication is available from the NASA Center for AeroSpace Information, 443-757-5802 }\end{array}$} \\
\hline
\end{tabular}

\section{SUPPLEMENTARY NOTES}

\section{ABSTRACT}

This paper provides an overview of the controls and diagnostics technologies, that are seen as critical for more intelligent gas turbine engines (GTE), with an emphasis on the sensor and actuator technologies that need to be developed for the controls and diagnostics implementation. The objective of the paper is to help the "Customers" of advanced technologies, defense acquisition and aerospace research agencies, understand the state-of-the-art of intelligent GTE technologies, and help the "Researchers” and “Technology Developers” for GTE sensors and actuators identify what technologies need to be developed to enable the "Intelligent GTE” concepts and focus their research efforts on closing the technology gap. To keep the effort manageable, the focus of the paper is on "On-Board Intelligence" to enable safe and efficient operation of the engine over its life time, with an emphasis on gas path performance.

\section{SUBJECT TERMS}

Turbofan engines; Sensors; Actuators; Fault detection; Engine control

\begin{tabular}{|c|c|c|c|c|c|}
\hline \multicolumn{3}{|c|}{ 16. SECURITY CLASSIFICATION OF: } & \multirow{2}{*}{$\begin{array}{l}\text { 17. LIMITATION OF } \\
\text { ABSTRACT } \\
\text { UU }\end{array}$} & \multirow{2}{*}{$\begin{array}{l}\text { 18. NUMBER } \\
\text { OF } \\
\text { PAGES } \\
19\end{array}$} & \multirow{2}{*}{$\begin{array}{l}\text { 19a. NAME OF RESPONSIBLE PERSON } \\
\text { STI Help Desk (email:help@sti.nasa.gov) } \\
\text { 19b. TELEPHONE NUMBER (include area code, } \\
\text { 443-757-5802 }\end{array}$} \\
\hline $\begin{array}{l}\text { a. REPORT } \\
\text { U }\end{array}$ & $\begin{array}{l}\text { b. ABSTRACT } \\
\text { U }\end{array}$ & $\begin{array}{l}\text { c. THIS } \\
\text { PAGE } \\
\text { U }\end{array}$ & & & \\
\hline
\end{tabular}



